\title{
EL CANDADO DEL 78: \\ PODEMOS ANTE LA MEMORIA Y LA HISTORIOGRAFÍA SOBRE LA RUPTURA DEMOCRÁTICA ${ }^{1}$
}

\author{
THE PADLOCK OF '78: \\ PODEMOS AND THE MEMORY \\ OF DEMOCRATIC RUPTURE
}

\author{
José Carlos Rueda Laffond \\ Universidad Complutense de Madrid
}

Entregado el 25-8-2015 y aceptado el 27/6/2016.

\begin{abstract}
Resumen: Este trabajo se aproxima al uso público de la historia en el discurso político y a las pugnas de memoria sobre la Transición española. Centra su estudio en el partido político Podemos. Como hipótesis fundamental plantea que su estrategia discursiva se caracterizó durante su proceso de creación y maduración durante 2014 por una apropiación y actualización populista de la categoría histórica de «ruptura democrática». Dicho término proviene del vocabulario de la oposición antifranquista de mediados de los años setenta. Esta progresiva recuperación y actualización fue fruto de una multiplicidad de factores donde incidieron la reflexión historiográfica, las revisiones del relato político o ciertas dinámicas de transmisión generacional donde participó la memoria militante. Desde ese supuesto, el artículo aborda diversas narrativas formuladas desde Podemos interpretándolas como prácticas de contra-memoria, en relación con el diseño de sus señas de identidad y su diagnóstico político.
\end{abstract}

\footnotetext{
${ }^{1}$ Este trabajo es resultado del Proyecto de Investigación «Memorias en segundo grado: posmemoria de la Guerra Civil, el franquismo y la Transición democrática en la sociedad española contemporánea», ref. CSO2013-41594-P (Mineco, Programa Estatal de Fomento de la Investigación Científica y Técnica de Excelencia).
} 
Palabras clave: Transición española, ruptura democrática, contra-memoria, historiografía.

\begin{abstract}
This article examines the public use of history and the struggles surrounding the memory of the Spanish transition, centered on the political party Podemos. The article hypothesizes that Podemos's discursive strategy has been characterized by a populist appropriation and update of the category of democratic rupture. This term emerges from the vocabulary of the anti-Francoist opposition of the mid-1970s. Its progressive recovery since the beginning of the twenty-first century has been the product of multiple factors, including historiographical reflection on revisions of the political story about rupture, and certain dynamics of its generational transmission in which the militant memory has taken part. From this hypothesis, the article addresses different narratives used by Podemos - for example, in relation to the design of their marks of identity and diagnoses for the present and future-, interpreting them as practices of counter-memory.
\end{abstract}

Key words: Spanish Transition, Democratic Breakdown, Counter-Memory, Historiography. 


\section{Introducción}

«Queremos un proceso constituyente para abrir el candado del 78». Tales palabras sirvieron el 16 de noviembre de 2014 como titular de portada del diario El País, donde también se apostillaba que «Pablo Iglesias promete acabar con el régimen de la Transición». La noticia glosaba el acto final de la Asamblea Ciudadana del partido político Podemos en la que, durante dos meses, se debatió su modelo político, ético y organizativo y se eligieron sus órganos de dirección nacional. Con este acto se cerraba una dinámica de estructuración interna que ponía punto final a una fase de inicial provisionalidad. Podemos había nacido a mediados de enero como «candidatura por la recuperación de la soberanía popular» con vistas a los comicios europeos del 25 de mayo. Surgió del impulso de distintos nombres vinculados al ámbito académico o periodístico, al activismo y a movimientos de protesta, como Juventud Sin Futuro o las $\mathrm{Ma}$ reas reivindicativas en la sanidad y enseñanza públicas. E, inicialmente, contó con el soporte de Izquierda Anticapitalista (IzAn), una pequeña formación en parte integrada como corriente en Izquierda Unida (IU) entre 1993 y 2008. Una resolución de su Secretaria Confederal había decidido apostar a finales de 2013 por una «alternativa anti-régimen (con) nuevos referentes políticos transversales» y «personalidades con proyección mediática» ${ }^{2}$. El documento se cerraba con el manifiesto fundacional «PODEMOS!», finalmente titulado «Mover ficha: convertir la indignación en cambio político» al hacerse público en prensa el 14 de enero.

El programa electoral de Podemos para las elecciones al Parlamento Europeo incluía propuestas que afectaban a la médula de la política española, como la revisión constitucional o el reconocimiento del derecho de autodeterminación. Estos puntos se complementaron con propuestas como la auditoria ciudadana sobre la deuda, la nacionalización de sectores estratégicos, la creación de una banca pública popular o la implementación de una renta básica universal. La formación obtuvo unos resultados destacables en aquellos comicios (cinco escaños y alrededor de 1’2 millones de votos, casi un $8 \%$ de los sufragios). Este hecho constituyó el arranque para un proceso de clara expansión. A finales de diciembre superó la barrera de los 300.000 inscritos. Previamente, diversas encuestas publica-

2 Izquierda Anticapitalista, «Resolución de la Secretaría Confederal», Enlace, 82, 2014, pp. 2-6 (disponible en http://www.zonaizquierda.org/X_docs/_CONTENIDOS/Podemos.pdf). 
das en el otoño evidenciaron una notable intención de voto directo (más del 15\%) o voto estimado (20-25\%), similar al que obtendrían el Partido Popular (PP) y el Partido Socialista Obrero Español (PSOE).

En términos de percepción ciudadana Podemos se ubicó claramente en el espacio de la izquierda ${ }^{3}$. Diversas connotaciones radicales (chavismo, radicalismo, simpatía filoetarra...) sirvieron desde el mes de junio de 2014 como etiquetaje reactivo para las críticas principalmente formuladas desde el entorno político, intelectual o periodístico próximo al PP. En otros casos las críticas frontales se formularon destacando la actualización de prácticas propias del leninismo autoritario en la gestación y maduración de Podemos ${ }^{4}$. Y, en paralelo, se multiplicaron las voces que destacaron que Podemos debía correlacionarse con un escenario de mutación definido por la crisis económica, las medidas de austeridad y la deslegitimación de la elite política a causa de los casos de corrupción. Otros acontecimientos - la muerte de Adolfo Suárez el 23 de marzo y la abdicación del rey Juan Carlos I el 2 de junio - amplificaron la sensación de fin de era. En tal contexto el periodista Raúl del Pozo afirmó que Podemos había «reventado el santo sepulcro de la Transición», o Casimiro García Abadillo, director del diario El Mundo, se preguntó si el futuro traería una tercera República o una segunda Transición ${ }^{5}$.

Las siguientes páginas se aproximarán al marco general del uso público de la historia. Es decir, a las formas en que el pasado se encuadra y explica en la esfera pública, a sus intencionalidades y a sus funciones pedagógicas y morales. Como destacó Nicola Gallerano ${ }^{6}$, este término incorpora un amplio inventario de aspectos imbricados con la gestión de los imaginarios colectivos. Sus implicaciones afectarían a la producción de sentido en el ámbito historiográfico en relación con la cultura política, a

${ }^{3}$ Centro de Investigaciones Sociológicas, Barómetro de octubre de 2014, Madrid, CIS, p. 17.

4 Véase, al respecto, el extenso ciclo de artículos críticos publicados por Antonio Elorza que se iniciaron días después de las elecciones europeas con «La ola», El País, 16 de junio de 2014.

5 R. del Pozo, «Monedero el villano», El Mundo, 10 de septiembre de 2014 (disponible en http://www.elmundo.es/opinion/2014/09/10/5410a59a22601dba1f8b459e.html); C. Abadillo, «La Segunda Transición o la III República», El Mundo, 30 de noviembre de 2014 (disponible en http://www.elmundo.es/opinion/2014/11/29/547a27e8e2704e661e8b4 592.html).

${ }^{6}$ N. Gallerano, «Storia e uso pubblico della storia», en N. Gallerano (Ed.), L'usso pubblico della storia, Milán, Franco Angeli, 1995, pp. 17-19. 
las prácticas de diseño o reciclaje narrativo, o a su mediatización y socialización.

Podemos está siendo objeto de un creciente interés bibliográfico durante 2015 y 2016, particularmente en lo referido al análisis de sus mecánicas de formación, vertebración, organización y atracción social ${ }^{7}$. Algunos de sus dirigentes más conocidos han reflexionado reiteradamente sobre su carácter como herramienta o método, capaz de aprovechar eficazmente una estructura de oportunidad y de coadyuvar en la conformación o estabilización de nuevas identidades políticas que trascendiesen el espacio ideológico clásico de la izquierda ${ }^{8}$. Otras reflexiones, en cambio, han resaltado su capacidad de actualización de algunos utillajes instrumentales procedentes del marxismo ${ }^{9}$, o bien la relevancia otorgada a los medios de comunicación, particularmente el televisivo ${ }^{10}$. En el presente trabajo se estimará que Podemos ha concitado también un imaginario simbólico sobre el presente y el pasado. Nuestra hipótesis se basa en la idea de que la estrategia discursiva planteada por esta organización durante 2014 incorporó y actualizó, como elemento medular, la categoría de ruptura democrática. Dicho concepto proviene del vocabulario de la oposición antifranquista de mediados de los años setenta, y habría sido re-contextualizado política e historiográficamente para facilitar una lectura comprensiva del pasado, sirviendo además de llave para establecer ciertos diagnósticos de actualidad y formular determinadas expectativas de futuro.

Desde este supuesto, el artículo se estructurará en tres partes entendidas como dimensiones complementarias. En la primera de ellas se apun-

7 Como aproximaciones de conjunto destacan J. I. Torreblanca, Asaltar los cielos: Podemos o la política después de la crisis, Madrid, Debate, 2015, J. Rivero, Podemos. Objetivo: asaltar los cielos, Barcelona, Planeta, 2015, Colectivo Politikon, Podemos. La cuadratura del círculo, Madrid, Debate, 2015, o Héloïse Nez, Podemos de l'indignation aux élections, París, Éditions Les petits matins. Otras perspectivas abordadas han sido las biográficas o las vinculadas a la sociología electoral: J. Rivero, Pablo Iglesias, biografía política urgente, Madrid, Stella Maris, 2016, o J. Fernández-Albertos, Los votantes de Podemos, del partido de los indignados al partido de los excluidos, Madrid, La Catarata, 2015.

${ }^{8}$ P. Iglesias, «Entender Podemos», New Left Review, julio-agosto de 2015, pp. 20-22.

9 D. Álvaro García, El método Podemos: marketing marxista para partidos no marxistas, Madrid, Última Línea, 2015.

10 V. Sampedro, «Podemos, de la invisibilidad a la sobre-exposición», Revista Teknocultura, 12, 1, 2015, pp. 137-154; o J. C. Rueda, «Podemos: relato, representación nacional y estrategias de divulgación política», Iberoamericana Quinqueecclesiensis, 14, 2016, pp. 163-176. 
tará un marco interpretativo general acerca del relato canónico sobre la Transición, su discusión historiográfica y contra-memorística y sus conexiones con el enfoque populista. El segundo apartado propondrá un recorrido histórico por los contenidos y derivaciones del vocablo ruptura democrática. Finalmente, la última sección situará dicho concepto en términos de reelaboración y actualización en tiempo presente, emplazándolo en relación con distintas narrativas de recuerdo generadas desde la dirección o el entorno intelectual de Podemos durante 2014 o en los primeros meses de 2015, es decir, coincidiendo con el proceso de maduración organizativa y vertebración sociocultural de esta formación política.

\section{Contra-memoria, crítica histórica y populismo como estrategias discursivas}

«La memoria y la imaginación sirven de proveedores y consumidores de sus recíprocas mercaderías» ${ }^{11}$. Esta afirmación debe relacionarse con la capacidad de la narrativa para conformar sentidos, naturalizar formas de percepción o reelaborar recuerdos y expectativas, subrayando su capacidad no tanto para denotar el mundo real, sino para significarlo. La Transición española ha sido explicada como escenario definido por la producción y socialización de relatos inclusivos. En esta lógica se ha estimado que las nociones de acuerdo, superación del trauma de la Guerra Civil mediante la reconciliación nacional o conciencia de nuevo comienzo actuaron como semánticas decisivas para la cultura política desde $1976^{12}$. Ya desde finales de los años setenta se estabilizó una narrativa pública que recalcó también las dinámicas de mutación institucional o el papel de las elites políticas. Ciertos acontecimientos - la actitud de Juan Carlos I ante el golpe de Estado de 1981, la adhesión a la Comunidad Económica Europea en 1985 o los eventos de 1992 - materializaron la plástica de una nueva España, moderna y dinámica, que parecía romper abiertamente con las inercias del pasado ${ }^{13}$. Y sobre esa visión se implementó, sobre todo

11 J. Bruner, La fábrica de historias. Derecho, Literatura, Vida, México, Fondo de Cultura Económica, 2003, p. 130.

${ }^{12}$ L. D. Edles, «Rethinking democratic transition: a culturalist critique and the Spanish case», Theory \& Society, 24, 1995, pp. 370-373.

${ }^{13}$ Cfr. con L. Elena Delgado, La nación singular. Fantasías de la normalidad democrática española, Madrid, Siglo XXI, 2014. 
desde la primera década del siglo XXI, una cualificación de la Transición entendida como matriz fundacional del tiempo presente y generadora de un contexto de desarrollo y bienestar.

En estas coordenadas el valor democracia adquirió una «categoría cuasi-mítica que ofrecía seguridad y eficacia organizativa para promover la cultura y el progreso, y orientar la vida individual o social» ${ }^{14}$. Su cualificación paradigmática $-\mathrm{y}$ también su referente moral- sería el consenso. Una noción que cabría entender como herramienta funcional decisiva para permitir el paso de la dictadura a la monarquía parlamentaria mediante el entendimiento entre sectores del reformismo posfranquista y las fuerzas mayoritarias de oposición. Pero, ante todo, el consenso se explicó como un imperativo sobre el que edificar el acuerdo entre ciudadanía y clase política en forma de contrato social. La subsistencia de esta tesis en términos de actualidad se ha trasladado hasta el presente. Quedó explícitamente expresada, por ejemplo, en la declaración conmemorativa del PP sobre el XXXVI aniversario de la Constitución en 2014, donde ésta fue presentada como «culmen de un largo proceso» histórico iniciado en 1812, «éxito sin precedentes» y como texto cuyo espíritu «debe preservarse siempre».

Dicha declaración constituye una muestra tardía del relato político hagiográfico sobre la Transición, y su directa apelación al orden constitucional fue respuesta a los dos grandes retos suscitados en 2014: el soberanismo catalán y el creciente eco social suscitado por Podemos. Los contenidos específicos de la reflexión de pasado de esta formación serán detallados en la última sección de este trabajo. Baste apuntar ahora algunos aspectos introductorios de su condición contra-memorística y de crítica histórica.

El término contra-memoria posee una clara inspiración foucaultiana. Debe relacionarse con su conocida discusión a las versiones normalizadoras y a las reglas normativas o epistemológicas que proveen un orden al discurso, le dotan de sentido y veracidad, y le capacitan para establecer un sistema de poder o una voluntad de exclusión. Frente a la potencialidad de la aparente objetividad, Foucault esgrimió la necesidad de construir una contra-narrativa desde abajo que aboliese las jerarquías del discurso y aportase sentido histórico mediante la negación de la ilusión teleológica ${ }^{15}$.

14 M. Ortiz, «Nuevos y viejos discursos de la Transición. La nostalgia del consenso», Historia Contemporánea, 44, 2011, p. 346.

15 M. Foucault, Dits et écrits, II, París, Gallimard, 1994, pp. 152-154. 
Desde este enfoque seminal, las prácticas de contra-memoria se han explicado en lógica de conflicto entre recuerdo presente (es decir, el expresado desde una memoria institucionalizada hegemónica) y ausente (la memoria marginada o derivada de culturas de resistencia y desafío). De este modo, la contra-memoria se caracterizaría por ser un espacio de afirmación y desestabilización capaz de reunir voces silenciadas y erigirlas en discusión política ${ }^{16}$.

El principal reparo que puede hacerse a esta concepción deriva de la complejidad histórica de la dialéctica entre memoria y contra-memoria, así como de la pluralidad de interacciones posibles, no necesariamente conflictivas, que pueden darse en el seno de los relatos dominantes, o en los producidos o asumidos por los sujetos subalternos ${ }^{17}$. En cualquier caso, la dicotomía memoria y contra-memoria ha estado presente en diversas consideraciones que han formulado una denuncia global de la cultura de la Transición, entendiéndola como paradigma hegemónico vigente desde inicios de los años ochenta. Un todo cultural caracterizado por la capacidad de asimilación, la producción de mercancías aproblemáticas o por el deseo de socializar una visión condescendiente del pasado orientada a desautorizar posibles voces de contestación y protesta ${ }^{18}$.

Este enfoque debe relacionarse con distintos trabajos que han destacado un claro sesgo de crítica a la metanarrativa transicional en el denominado Movimiento del $15 \mathrm{M}$, la cascada de protestas ciudadanas vividas en España en la primavera de 2011. Además de su carácter ideológicamente transversal e intergeneracional, se ha destacado el componente de re-significación histórica presente en este movimiento, que habría problematizado el imaginario idílico de la Transición rechazando las visiones complacientes sobre un pasado ahora percibido como dique discursivo de contención social ${ }^{19}$. Paralelamente, se ha detectado en las prácticas del $15 \mathrm{M}$ un fenómeno de recuperación performativa de estéticas y estrategias activistas inspiradas en la protesta colectiva de mediados de los años se-

${ }^{16}$ P. Hutton, History as an Art of Memory, Vermont, University Press of New England, 1993, pp. 110-116.

17 J. E. Bodnar, Remaking America. Public Memory, Commemoration, and Patriotism in the Twentieth Century, Princeton, Princeton University Press, 1992, pp. 13-20.

${ }^{18}$ C. Acevedo y otros autores, CT o la Cultura de la Transición. Crítica a 35 años de cultura española, Barcelona, Debolsillo, 2012.

19 V. Sampedro y J. Lobera, «The Spanish 15-M Movement: a consensual dissent?», Journal of Spanish Cultural Studies, 15, 1-2, 2014, pp. 61-80. 
tenta ${ }^{20}$. Dicho rescate e instrumentación iconográfica habría actuado como cauce para discutir la legitimidad fundacional del sistema representativo y de su cultura consensual, en parte readecuando la retórica presente en la enunciación antifranquista ${ }^{21}$.

El 15M enfatizó una serie de leitmotiv que fueron subsumidos en el discurso público de Podemos de 2014 en aspectos como la denuncia de las elites o los déficits democráticos. El 15M fue prontamente evaluado por los futuros dirigentes del partido. Para Juan Carlos Monedero, por ejemplo, constituyó la expresión de la necesidad de reinvención democrática, el arranque del «reloj» del cambio o la escenificación del «fin de los consensos de la Transición» 22 . Por su parte, Íñigo Errejón lo explicó en 2011 como fenómeno eminentemente cultural que evidenciaba la «posibilidad de una contra-hegemonía», en el sentido gramsciano del término, «capaz de generar nuevas mayorías» ${ }^{23}$. Y posteriormente, como directa expresión de un «discurso contra-hegemónico» aglutinante para una nueva identidad dirigida a quebrar «el sentido instituido»; o - en este caso, en palabras de Pablo Iglesias - como evidencia de una «nueva cultura impugnatoria» que trascendería la dicotomía clásica entre izquierda/derecha ${ }^{24}$. Ya en abril de 2015 Íñigo Errejón actualizó su perspectiva valorativa sobre el $15 \mathrm{M}$, implicándola en este caso con la emergencia de Podemos y en clave de lugar de memoria para esta formación política ${ }^{25}$.

En los textos de Errejón o Iglesias son perceptibles las influencias teóricas de Carl Schmitt sobre dicotomías en las identidades políticas, de la primera generación de los Estudios Culturales británicos, de Slavoj Žižek

${ }^{20} \mathrm{~K}$. Kornetis, «Is there a future in this past? Analyzing 15M's intricate relation to the Transición», Journal of Spanish Cultural Studies, 15, 1-2, 2014, pp. 83-98.

${ }^{21}$ G. Labrador, «¿Lo llamaban democracia? La crítica estética de la política en la Transición española y el imaginario de la historia en el 15-M», Kamchatka, 4, 2014, pp. 11-61 (disponible en https://ojs.uv.es/index.php/kamchatka/article/view/4296).

22 J. C. Monedero, Dormíamos y despertamos. El 15M y la reinvención de la democracia, Madrid, Nueva Utopía, 2012, pp. 13-57.

${ }^{23}$ I. Errejón, «El 15-M como discurso contrahegemónico», Encrucijadas, 2, 2011, p. 127. Un enfoque equiparable al de Errejón, e igualmente temprano en el tiempo sobre el Movimiento 15M, es el de X. Domènech, «Crisis de hegemonía y movimientos de resistencia», Papeles de Relaciones Ecosociales y Cambio Global, 116, 2011/12, pp. 63-74.

24 I. Errejón, «Podemos como práctica cultural emergente frente al imaginario neoliberal: hegemonía y disidencia», IC Revista Científica de Información y Comunicación, 11, 2014, pp. 26; Iglesias, op. cit., pp. 18-19.

25 I. Errejón, «Crisis de régimen y hegemonía», La Circular, abril de 2015 (disponible en http://lacircular.info/crisis-de-regimen-y-hegemonia/). 
sobre movilización o cultura popular, o de Edward Said sobre representación de la otredad como mecanismo narrativo que promueve la afirmación inclusiva. Y, muy particularmente, del posmarxismo de Chantal Mouffe y Ernesto Laclau. De hecho, La razón populista constituye el texto de cabecera para entender el carácter de Podemos como método o herramienta. Laclau revaloriza en esa obra el concepto populismo como práctica cultural frente a su habitual denotación peyorativa como demagogia o ideología política subdesarrollada. No obstante, el politólogo argentino evitó una definición precisa, afirmando que debe entenderse como acción discursiva susceptible de actuar como aspiradora de demandas sociales ${ }^{26}$.

El instrumento central en la iniciativa populista sería entonces el significante vacío, el espacio semántico dúctil donde cabe acoplar reivindicaciones heterogéneas hasta configurar una cadena de equivalencias más amplia que aporte identidad renovada al sujeto popular. Esta acción conlleva sustanciar «significados políticos relevantes» desde la afinidad y la exclusión a través de la afirmación de un Nosotros insatisfecho frente a un Otro. Semejante ejercicio de reconfiguración simbólica lo detectó Laclau en distintos escenarios históricos: en el proyecto rooseveltiano y el nuevo conservadurismo estadounidense de finales del siglo XX, en la estrategia del Partido Comunista Italiano tras el Giro de Salerno de 1944, o en la transferencia de voto desde el Partido Comunista Francés al Frente Nacional desde los años noventa ${ }^{27}$.

La incapacidad institucional para absorber demandas insatisfechas actuaría como factor de «ruptura populista» con el orden social existente. Esta última noción está vacía de especificidades históricas. No cabe entenderla como momento fundacional y, menos aún, como categoría absoluta, lo cual permite ubicar el relato de contra-memoria, en cuanto condición discursiva, en un juego flexible de equivalencias y oposiciones ${ }^{28}$. En la narrativa pública de Podemos, el significante ruptura se asimilará con nueva política demandada en el 15M. Simultáneamente, puede entenderse como concepto que reúne la crítica a la hegemonía del PP y PSOE, las fuerzas que habrían encarnado a la casta, otro de los significantes más

26 A. Salinas, «Populismo, democracia, capitalismo: la teoría política de Ernesto Laclau», Crítica Contemporánea, 1, 2011, p. 183.

${ }^{27}$ E. Laclau, La razón populista, Buenos Aires, Fondo de Cultura Económica, 2005, pp. 32-35, 163-168 y 115.

${ }^{28}$ E. Laclau y Ch. Mouffle, Hegemonía y estrategia socialista. Hacia una radicalización de la democracia, Madrid, Siglo XXI, 1987, pp. 181 y 195. 
reconocibles del discurso público de Podemos en 2014. Y, en fin, ruptura enlazaría con una concepción historiográfica de lo transicional entendida como continuidad del grueso del personal político franquista y de sus elites económicas, adquiriendo así un rango trascendente frente a una percepción de historia frustrada: conseguir quebrar auténticamente la dictadura.

\section{Genealogía histórica y lecturas historiográficas de la ruptura democrática}

Aunque el término ruptura democrática se popularizó entre 1974 y 1976, su connotación recorre toda la historia del antifranquismo. En términos esenciales sintetizaba la intención de liquidar la dictadura y abrir un proceso constituyente. En esta lógica, ruptura reflejó un propósito transversal ${ }^{29}$. No obstante, la disparidad de intereses en la oposición, sus tensiones, reacomodos o ambigüedades, sugieren que, más que de una semántica unívoca, haya que hablar de un término flexible ante estrategias y expectativas plurales. De ahí su carácter como significante dúctil donde se ubicaron identidades diversas que abarcaron desde opciones moderadas a las familias socialistas o a grupos de izquierda radical. Por ejemplo, el PSOE aprobó en el Congreso de Suresnes en octubre de 1974 un programa que mencionaba explícitamente el objetivo de la ruptura democrática. Sin embargo, la organización que capitalizó con más claridad ese concepto fue el Partido Comunista de España (PCE), inscribiéndolo en una retórica que apeló a la confluencia entre solidaridades y expectativas de un sujeto amplio y heterogéneo: el sujeto popular (trabajadores y masas ciudadanas), definible en oposición a un anti-pueblo compuesto por el régimen y sus oligarquías ${ }^{30}$.

El vocablo ruptura presentó dos modulaciones bien diferenciadas en el discurso comunista. La primera abarcó de 1972 a 1975. La resolución política aprobada en su VIII Congreso afirmó que, frente a «la imposición juancarlista», la solución «no consiste en desarrollar las leyes e instituciones fascistas, sino en acabar con ellas mediante una ruptura

29 S. Juliá, «Orígenes sociales de la democracia en España», Ayer, 15, 1994, p. 186.

30 R. Cruz, «Como Cristo sobre las aguas. La cultura política bolchevique en España», en A. Morales Moya (Ed.), Ideologías y movimientos políticos, Madrid, Nuevo Milenio, 2001, pp. 190-191. 
democrática $»^{31}$. Esta lectura se enmarcaba en otro de los análisis planteados en 1972: el relativo al centrismo, es decir, a las veleidades aperturistas presentes en la dictadura que Santiago Carrillo presentó como mera estrategia de reacomodo y adaptabilidad. Frente al riesgo de «cambio desde arriba», el PCE lanzó la consigna de una «revolución política» formulándola como movilización ciudadana incruenta dirigida a «apoderarse de la calle (para presionar) contra el núcleo de poder» ${ }^{32}$. Una vez lograda su caída, se instauraría un gobierno provisional de coalición que convocaría elecciones a Cortes Constituyentes.

Este esquema respondía en buena medida al modelo desarrollado en la Italia posfascista, basado en el entendimiento con la Democracia Cristiana (que el PCE presuponía sería la opción conservadora mayoritaria en España), y en el pacto circunstancial entre clases trabajadoras, funcionariado, Iglesia y tejido empresarial. Ya en abril de 1974, Santiago Carrillo volvió a insistir en la incapacidad de la dictadura para iniciar ninguna senda reformista. «El problema no es de aperturas, sino de rupturas», consideró, al tiempo que destacaba la corrupción y la crisis económica como factores coadyuvantes en el colapso del franquismo ${ }^{33}$. Otro informe anterior resulta especialmente interesante en este sentido, al sintetizar la idea de ruptura desde una óptica discursiva de confrontación dual, similar a la empleada en el relato generalista de Podemos en 2014. Insistía en la deslegitimación del régimen por el divorcio entre clase política y pueblo, en la oposición entre oligarquía y ciudadanía, y en la tensión entre lucha de masas e «imposición transitoria» encarnada en la sucesión ${ }^{34}$. Más allá de su triunfalismo, reiteraba el papel del partido como artífice para un acuerdo transversal. Este culminó históricamente en julio de 1974 al constituirse la Junta Democrática, cuyo manifiesto recogió los objetivos de gobierno provisional, amnistía o consulta sobre forma de Estado.

Un último texto - el Manifiesto Programa aprobado en 1975- engarzó la reivindicación comunista sobre la ruptura en unas coordenadas simbólicas y programáticas más amplias. Aquel documento se elaboró desde 1972 y recuperó la noción de democracia política y social, un referente que venía empleándose desde mediados de los años sesenta. Conce-

31 Partido Comunista de España, VIII Congreso, Bucarest, Poligráfica, 1972, p. 328.

32 S. Carrillo y D. Ibárruri, Hacia la libertad, París, Éditions Sociales, 1972, pp. 50-51.

33 S. Carrillo, Hacia el post-franquismo, París, Ebro, 1974, pp. 47-48.

34 V. Suárez y G. López Raimundo, Alternativa democrática y lucha de masas, s. 1., PCE, 1973, pp. 26-43. 
bida como fase de transición hacia el socialismo, dicha fórmula era explicada en términos de colaboración entre clases trabajadoras y estratos de las clases medias orientada a la eliminación del capitalismo monopolista. Paralelamente, sustanciaba los objetivos del PCE en el hipotético proceso constituyente que debía cerrar la dictadura: el reconocimiento de libertades y derechos (entre ellos, el de autodeterminación), la república federal como forma de Estado, la nacionalización de la banca y otras grandes empresas, la reforma del sistema fiscal o el reforzamiento de los servicios públicos.

El término ruptura democrática presentó una modulación distinta desde comienzos de 1976. El PCE lo siguió utilizando, pero readaptándolo a un escenario definido por el diseño legal del reformismo, el temor a la marginación y en una estrategia que combinó la presión social - notable en la primera mitad del año- y el interés por negociar. Ya en enero, su discurso introdujo una primera matización, al reconocer que la muerte de Franco suponía un cambio importante y permitía mayor tolerancia. Tal afirmación puede explicarse como consecuencia de los contactos indirectos habidos desde 1974 entre el entorno de Juan Carlos y Santiago Carrillo. En semanas posteriores comenzó a sugerirse que la ruptura podía resolverse mediante «un simple decreto», y ya en marzo se introdujo la matización semántica de «ruptura pactada» como fórmula de encuentro entre la oposición, representantes de la Iglesia y el Ejército y sectores reformistas procedentes de la dictadura. Este giro se reafirmó a finales de julio, tras la designación de Adolfo Suárez, cuando Carrillo defendió el diálogo con el nuevo gobierno para establecer las condiciones de una «transformación democrática» ${ }^{35}$. Finalmente, en vísperas del referéndum del 15 de diciembre, redactó un breve trabajo donde enfatizó la renuncia a exigir responsabilidades por la dictadura, rebajó al nivel de «no esencial» la cuestión de la forma de Estado, y aceptó que el proyecto para la reforma política aprobado en Cortes podía sustanciar la ruptura con el franquismo ${ }^{36}$.

El breve itinerario que hemos trazado por el concepto ruptura sugiere varias cuestiones. Por un lado, su contenido maleable, que abarcó desde el propósito de levantamiento popular y configuración de un contrapoder hasta la aceptación del reformismo. Y, por otra parte, su complejidad en

35 S. Carrillo, De la clandestinidad a la legalidad, s. 1., PCE, 1976, p. 9.

36 S. Carrillo, Qué es la ruptura democrática, Barcelona: La Gaya Ciencia, 1976, pp. 38-39 y 49 . 
términos de balance historiográfico. Frente a la lectura restringida al protagonismo de las elites, la superación del franquismo se ha explicado destacando la incapacidad de reproducción del régimen y la presión democratizadora desde abajo ${ }^{37}$. En esta lógica se ha considerado que la dinámica de cambio asimiló elementos sustanciales planteados en la categoría de ruptura por el $\mathrm{PCE}^{38}$. Esta visión contrasta con la perspectiva historiográfica que ha advertido a la Transición como fruto del reformismo adaptativo, donde la oposición fue cooptada por las elites posfranquistas asegurándose permanencias y continuidades clientelares. Desde esta otra óptica, el proyecto para la reforma política de finales de 1976 ha sido tildado de pieza maestra en un modelo asimétrico controlado por las instituciones del Estado frente a la presión social y la oposición, cuyas demandas - en un caso implicadas con la relativa tradición republicana en el PSOE, y en otro con la ambigua noción de «democracia política y social» manejada por el PCE - habrían quedado neutralizadas ${ }^{39}$. Desde coordenadas interpretativas hasta cierto punto equiparables, se ha llamado la atención acerca de los desajustes existentes entre algunas claves de la semántica distintiva del cambio político de mediados de los años setenta y las etiquetas que después han actuado como leitmotiv característicos a la hora de dar sentido histórico dominante a la Transición. Como ha destacado Juan Antonio Andrade conviene no soslayar que el vocabulario tópico manejado en los movimientos sociales más dinámicos del tardofranquismo o del año 1976 se definió por el uso de unas nociones muy diferentes a las de reforma pactada, consenso, concertación o monarquía parlamentaria, las categorías prototípicas asignadas con posterioridad como marcas distintivas a la Transición democrática ${ }^{40}$.

Todo este debate debe inscribirse en un marco sobre uso público de la historia caracterizado por la polémica cuyas raíces pueden retrotraerse hasta mediados de los años ochenta, si bien su eclosión se produjo inicios del siglo XXI. En este escenario incidieron diversos elementos: el revisio-

37 P. Ysàs, «La Transición española. Luces y sombras», Ayer, 79, 3, 2010, pp. 31-57; I. Saz, Las caras del franquismo, Granada, Comares, 2013, pp. 169-185.

${ }^{38}$ C. Molinero, «La Transición y la renuncia a la memoria democrática» Journal of Spanish Cultural Studies, 11, 1, 2010, p. 41.

${ }^{39}$ F. Gallego, El mito de la Transición. La crisis del franquismo y los orígenes de la democracia (1973-1977), Barcelona, Crítica, 2008, pp. 16-17, 380-381 y 704.

40 J. A. Andrade, El PCE y el PSOE en (la) transición. La evolución ideológica de la izquierda durante el proceso de cambio político, Madrid, Siglo XXI, 2012, pp. 51-52. 
nismo crítico y la discusión sobre los costes del consenso en sectores de la izquierda, la institucionalización de la memoria oficial sobre la Transición, la eclosión del movimiento memorialista y la recuperación simbólica de la cultura militante. Es aquí donde debe emplazarse la transferencia y reciclaje narrativo de la categoría de ruptura democrática y su interiorización en el relato manejado por Podemos durante 2014.

De entre los partidos que jugaron un papel relevante la Transición probablemente fue el PCE el que se sometió a mayor relectura crítica. En su XIV Congreso (1995) reconoció la frustración de las previsiones del $M a$ nifiesto Programa, afirmándose entonces que su fracaso fue consecuencia de un excesivo pragmatismo, de la presión sistémica y de las divisiones entre las fuerzas de oposición. Como resultado de aquel hecho se habrían reforzado los poderes económicos, se dio continuidad a los aparatos del Estado y se produjo la aceptación de la monarquía. Esta narrativa de revisión y crítica política debe relacionarse con las denuncias de IU a la derechización del PSOE y con el frustrado objetivo del sorpasso durante la segunda mitad de los años noventa. Además, también constituyó una reacción al diseño de un discurso de memoria desde el PP volcado en rentabilizar el recuerdo positivo de la Transición. Todo ello desembocó desde 1996 en una notable reorientación de las políticas de memoria, en lo que se ha categorizado como la fractura del pacto no escrito para evitar la instrumentalización del pasado ${ }^{41}$.

En estas coordenadas se emplazó alguna discusión pública sobre el carácter modélico de la Transición o su incidencia en la calidad democrática posterior, como ocurrió en el debate periodístico cruzado entre Javier Pradera, Vincenç Navarro y Javier Tusell en 2000. Sin embargo, el eje de la polémica memorialista se situó en la represión durante la Guerra Civil y el franquismo, una cuestión donde el eco de la Transición parecía ocupar una posición periférica aunque evidenciando considerables distancias entre los enfoques de izquierda. Por ejemplo, Esquerra Republicana de Catalunya y el PSOE plantearon concepciones opuestas durante la tramitación de la Ley de Memoria Histórica. La primera presentó en 2005 un proyecto cuyo preámbulo denunciaba «la continuidad de la legalidad franquista» o la inexistencia de perdón del Jefe del Estado «por los crímenes cometidos». El PSOE impulsó, en cambio, la redacción final de 2007 que esti-

${ }^{41}$ C. Humlebaeck, «Usos políticos del pasado reciente durante los años de gobierno del PP», Historia del Presente, 3, 2004, p. 158. 
maba que era el «espíritu de la Transición» el que daba sentido a aquella ley. Y fue, en fin, en este mismo contexto donde se sistematizó la crítica al «mito de la Transición» como relato contra-memorístico. En él se tipificaron los argumentos esenciales de lo que ha venido en llamarse la narrativa oficial -el papel providencial de Suárez; la transmutación del consenso en ideología de moderación; la idealización del modelo transicional...-, presentando a la clase política conservadora y socialista en un plano de equivalencia en el uso de la Transición como referente legitimador ${ }^{42}$.

Otra deriva paralela de la eclosión memorialista fue la proliferación de memorias militantes de izquierda radical. Dicha etiqueta ha englobado a un amplio abanico de pequeñas organizaciones ubicadas a la izquierda del PCE que asumieron en los años setenta proyectos alternativos con distinta gradación revolucionaria o maximalista. En esta lógica, la dimensión de ruptura que manejaron superaba no sólo los límites de un modelo de representatividad democrática parlamentaria, sino también el etapismo consensual entonces propugnado por el $\mathrm{PCE}^{43}$.

Alguno de estos grupos han sido objeto de recuperación desde un enfoque autobiográfico colectivo. Es el caso de la publicación promovida desde la asociación de memoria de antiguos miembros del Partido del Trabajo de España (PTE). En esta obra, la lucha por la ruptura se concebía como dinámica con múltiples dimensiones (formas de oposición a la dictadura, presencia electoral desde 1977), donde los frentes de movilización (sindical, estudiantil, vecinal, feminista y nacionalista) conformaron los potenciales motores del cambio. En cambio, la Transición era explicada como «reforma dentro de un sistema de dominación» definida por el deseo de «evaluar y minimizar riesgos», combinando represión selectiva y desactivación colectiva ${ }^{44}$. El PTE - surgido de las escisiones maoístas en el PCE vividas a mediados de los años sesenta - planteó entre 1973 y 1975 una estrategia basada en la coordinación de las protestas sectoriales desde un frente popular o antifascista, donde podrían incluirse de modo subordinado sectores de clase media. Y aunque finalmente acabó conflu-

42 B. André-Bazzana, Mitos y mentiras de la Transición, Madrid, El Viejo Topo, 2006, pp. 198.

${ }^{43}$ El estudio más actualizado sobre la izquierda radical es el de G. Wilhelmi, Romper el consenso. La izquierda radical en la Transición (1975-1982), Madrid, Siglo XXI, 2016.

${ }^{44}$ Asociación de Memoria Histórica del PTE-JGR, La lucha por la ruptura democrática en la Transición, Madrid, Asociación de Memoria Histórica del PTE-JGR, 2010, pp. 11-48. 
yendo en la Junta Democrática, asumió los objetivos de desarticular el aparato policial franquista y depurar responsabilidades por la dictadura.

Otro ejemplo de narrativa biográfica colectiva fue confeccionada por viejos militantes de la Liga Comunista Revolucionaria (LCR) desde un estudio descriptivo centrado en el debate político. En este texto se resalta el mantenimiento de la estrategia rupturista tras 1978, junto a una explícita reivindicación de que los problemas de presente enraizarían con cómo se realizó la Transición ${ }^{45}$. La actuación de la LCR se caracterizó por adecuar algunos postulados de tradición trotskista al entorno del tardofranquismo. Su discurso partió de una lectura basada en la agudización de la lucha de clases donde la opción reformista aparecía como mecanismo de neutralización burguesa frente a la presión popular. Esta tesis ha sido reiterada en otras reflexiones recientes, por ejemplo por parte del antiguo militante de esta organización Jaime Pastor, al subrayar como factor concluyente para el fracaso de la ruptura en 1976 la contención de los movimientos sociales por parte del PSOE y el PCE por su miedo a una huelga general que forzase un proceso constituyente dirigido desde un «bloque de intereses» alternativo al dominante ${ }^{46}$.

\section{Podemos: teoría y práctica de posmemoria de la ruptura democrática}

José Manuel Roca ${ }^{47}$ ha destacado el componente generacional como factor de homogeneidad en la izquierda radical de los años setenta, soldado en torno a la oposición al franquismo y frente a la «inanidad revolucionaria» de la vieja dirigencia del PCE. En el caso de la LCR existiría, además, una genealogía directa con Podemos, tanto orgánica - por su conexión con IzAn, heredera directa de aquella formación-, como intelectual, gracias a la labor de autores como Jaime Pastor, que han servido de bisagra entre las experiencias de los setenta y las de inicios del siglo XXI.

45 M. Caussa y R. Martínez (Eds.), Historia de la Liga Comunista Revolucionaria (1970-1991), Madrid, Viento Sur, 2014, pp. 16 y 111-129.

46 J. Pastor, «Una transición asimétrica. A propósito de El mito de la transición de Ferrán Gallego», El Viejo Topo, 252, 2009, pp. 54-55.

47 J. M. Roca, «Una aproximación sociológica, política e ideológica a la izquierda comunista revolucionaria en España», en J. M. Roca (Ed.), El proyecto radical. Auge y declive de la izquierda revolucionaria en España (1964-1992), Madrid, Catarata, 1994, p. 33. 
Víctor Sampedro ha explicado, por su parte, la dirigencia de Podemos como un ensamblaje de retales ideológicos y prácticas vitales, donde se habría producido el encuentro entre la generación del desencanto socialista, que rompió frontalmente «con la herencia franquista» y honró «a los abuelos republicanos», y la generación de los jóvenes trastocados en «desencajados del régimen del $78 »^{48}$. Y al glosar la movilización organizada por Podemos en la Puerta del Sol de Madrid el 31 de enero de 2015, el miembro del Consejo Ciudadano Eduardo Maura enfatizó la afinidad espacial existente entre aquella concentración y la de los indignados de 2011, resaltando la experiencia y el poso generacional de los nacidos en 1945-55, «aquellos que vivieron de primera mano la Transición». Según Maura, «hubo encuentros inesperados y se compartieron historias. Se escuchó aquello de esto me recuerda a los setenta. (Era como sî) asistiéramos a una segunda oportunidad, que no es lo mismo que una segunda Transición» ${ }^{49}$.

Las interrelaciones entre generaciones, percepciones de recuerdo colectivo y dinámicas de cambio histórico han sido resaltadas en algunos ensayos académicos a propósito de la Transición o ante la eclosión memorialista de inicios del siglo XXI. En el primer caso se han destacado los fenómenos de trauma de guerra heredado y de vivencia personal de postguerra para entender la negociación simbólica entre enfoques ideológicos diferenciados durante la segunda mitad de los años setenta respecto a la socialización del discurso sobre reconciliación nacional ${ }^{50}$. En el segundo caso se ha apuntado, en cambio, una reacción revisionista de la generación posterior frente a ese tratamiento consensual sobre la guerra o el franquismo, poniendo el foco en las tensiones asociadas al recuerdo de la violencia $^{51}$. En todo caso, debe subrayarse que las memorias generaciona-

48 D. Ayllón, «Víctor Sampedro: el mayor riesgo de Podemos es que funcione de arriba abajo», La Marea, 31 de diciembre de 2014 (disponible en http://www.lamarea. com/2014/12/31/victor-sampedro-el-mayor-riesgo-de-podemos-es-que-funcione-de-arribaabajo/).

49 E. Maura, «¿Por qué es ahora? Crónica no oficial de la Marcha del Cambio?», El Huffington Post, 3 de febrero de 2015 (disponible en http://www.huffingtonpost.es/eduardo-maura/por-que-es-ahora-cronica-_b_6593236.html).

50 P. Aguilar, Políticas de memoria y memorias de la política, Madrid, Alianza Editorial, 2008, p. 34.

51 J. Aróstegui, «Traumas colectivos y memorias generacionales. El caso de la guerra civil», en J. Aróstegui y F. Godicheau (Eds.), Guerra Civil. Mito y memoria, Madrid, Marcial Pons, 2006, p. 80. 
les no conforman compartimentos estanco. Este hecho permite entender la confluencia entre vivencias múltiples en las coordenadas de la posmemoria, un término en que el que el prefijo post- no haría alusión a un mero emplazamiento diacrónico, sino que indicaría la existencia de procesos de encuentro, diálogo, apropiación, readaptación o reciclaje entre culturas generacionales diversas ${ }^{52}$.

En este sentido cabe considerar que el relato de pasado en Podemos fue fruto de una simbiosis entre memoria de la generación del posfranquismo y de la postransición a través de la devaluación y revalorización de los paradigmas discursivos de reforma y ruptura, así como en relación con la cristalización de nuevas formas de identidad política. En este sentido, las referencias al pasado se encuadraron en un ropaje formal inédito -el logo de los círculos, el color morado...-, que no se inspiraba en referentes iconográficos ligados a la tradición de izquierdas y que resultaba coherente con el rechazo del discurso de Podemos a las etiquetas ideológicas clásicas. Este hecho es afín a la estrategia populista comentada en la primera sección de este artículo. Paralelamente, en el diseño de ese relato de pasado incidieron también algunos trabajos de investigación histórica o ensayo sociológico - muy particularmente los ya mencionados de $\mathrm{Fe}$ rrán Gallego, André-Bazzana o Acevedo-, así como de crítica cultural o ensayo histórico, con frecuencia enmarcados en la tradición y enfoques de los Estudios Culturales ${ }^{53}$.

52 M. Hirsch, Family Frames: Photography, Narrative and Postmemory, Cambridge, Harvard University Press, 1997.

53 Entre estas obras cabe mencionar el ensayo pionero desde un enfoque de crítica política coyuntural a la la Transición de G. Morán, El precio de la Transición, Barcelona, Planeta, 1991. Con posterioridad, cabe citar también los estudios de T. Vilarós (Mono del desencanto. Una critica cultural de la transición española, 1973-1993, Madrid, Siglo XXI, 2002), hasta los trabajos de X. Díez («La disolución de la historia oficial de la Transición», Spagna Contemporanea, 26, 2004, pp. 241-255), L. Castro (Héroes y caídos. Políticas de la memoria en la España contemporánea, Madrid, La Catarata, 2008), A. Medina (Exorcismos de la memoria. Políticas y poéticas de la melancolía en la España de la transición, Madrid, Ediciones Libertarias, 2001), E. Subirats (Intransiciones. Crítica de la cultura española, Madrid, Biblioteca Nueva, 2002), o los ensayos compilados en J. R. Resina (Ed.), Disremembering the Dictatorship: the Politics of Memory in the Spanish Transition to Democracy, Amsterdam-Atlanta, Rodolpi, 2001). Para una crítica de estas obras, S. Juliá, «Cosas que de la Transición se cuentan», Ayer, 79, 3, 2013, pp. 297-319, y respecto a la redición del ensayo de Morán, J. F. Fuentes, «Transición, democracia y nihilismo», Revista de Libros, abril de 2016 (disponible en http://www.revistadelibros.com/articulos/transicion-democracia-y-nihilismo). 
A partir de ahí, las prácticas de revisión histórica desarrolladas desde el entorno político e intelectual de Podemos incorporaron dos puntos de vista complementarios esenciales: por un lado, la consideración de que la reflexión sobre ciertas raíces de pasado serían capaces de explicar situaciones de presente, $y$, por otro, la actualización del concepto de ruptura democrática entendido como proyecto de futuro. Sendos ensayos de tono divulgativo - los libros Disputar la democracia, de Pablo Iglesias, y La transición contada a nuestros padres, de Juan Carlos Monedero- constituirían las muestras de introspección histórica más relevantes propuestas desde la dirigencia del partido en aquel contexto.

El primero fue básicamente redactado en el verano de 2013, publicándose en el otoño de 2014 como ensayo generalista. El texto estaba dedicado, entre otras personas, a su abuelo Manuel, combatiente en la Guerra Civil, y tras ella condenado a muerte, preso durante cinco años, militante del PSOE clandestino y, ya en los años ochenta, hombre «orgulloso de sus ideales, (aunque) despreciando a los jóvenes dirigentes de su partido». Este trasfondo de homenaje, en clave de posmemoria reivindicativa de quienes perdieron la guerra, vertebra la narrativa de Disputar la democracia. El libro establecía una perspectiva de largo recorrido que, arrancando del $15 \mathrm{M}$, se retrotrae hasta finales del siglo XIX mediante un hilo conductor diáfano: una suerte de tensión histórica permanente entre déficit y aspiración democrática durante la contemporaneidad española. En esas coordenadas se situaba la lectura de Iglesias sobre la Transición, directamente derivada de las reflexiones ya apuntadas de Ferrán Gallego o Jaime Pastor, valorándola como proceso asimétrico e insuficiente, saldado con la continuidad de las elites económicas y el reacomodo de las políticas ${ }^{54}$.

Disputar la democracia concluía sus páginas caracterizando como «contrarrevolución» a los efectos provocados por la crisis de 2008 sobre el Estado del Bienestar, en paralelo a la discusión de las viejas legitimidades heredadas de 1978. Sobre esas bases se justificaría la necesidad de Podemos, según Iglesias. El libro puede compararse con el sentido de oportunidad de Eurocomunismo y Estado, el bestseller de Santiago Carrillo escrito en el otoño de 1976 durante su clandestinidad madrileña y que fue publicado en vísperas de las elecciones de $1977^{55}$. De hecho, ambos ensayos coincidían en una similar reivindicación del Gramsci interesado por

${ }^{54}$ P. Iglesias, Disputar la democracia. Política para tiempos de crisis, Madrid, Akal, 2014, pp. 104, 110-111 y 186.

55 S. Carrillo, Eurocomunismo y Estado, Barcelona, Crítica, 1977. 
los fenómenos culturales de la generación y socialización de consensos o en el énfasis sobre una dimensión de lo democrático que trascendiese el juego parlamentario.

La Transición entendida como frustración histórica y mito narrativo compusieron, por su parte, los leitmotiv centrales del ensayo de Juan Carlos Monedero, una obra donde la intencionalidad de la posmemoria no se deriva de la directa apelación personal, sino del rechazo al silencio generacional y al acomodo cultural de los padres tras 1975 desde la reivindicación de la memoria doliente de los abuelos. Esta obra puede categorizarse como ejemplo de contra-memoria que entiende la Transición como derivada condicionada por el franquismo y como pretexto justificativo del sistema imperante en los últimos treinta y cinco años. Y aunque aquel texto fue publicado meses antes de la fundación de Podemos, explicitaba un enfoque selectivo sobre el pasado que estaría directamente relacionado con la cosmovisión y el léxico socializado desde la formación, o por otros ensayos críticos. En este sentido, el marco interpretativo asumido en el libro de Monedero se caracterizaba por el énfasis en una cosmovisión nutrida de déficits sistémicos y que reclamaba una movilización reactiva que recuperase lo que habría quedado frustrado en los setenta: la posibilidad de ir más allá de «una salida pacífica y neutralizada a la dictadura del general Franco» ${ }^{56}$.

La Asamblea Ciudadana de Podemos celebrada durante el otoño de 2014 aprobó una hoja de ruta estratégica con vistas a los distintos procesos electorales previstos para 2015. Establecía como meta la «apertura popular y constituyente» frente a la crisis orgánica de un modelo institucional definido por la «descomposición política y moral» de sus elites, el agotamiento del modelo bipartidista, las tensiones territoriales o la vulneración de los derechos socioeconómicos. En diversas entrevistas o intervenciones realizadas coincidentes con la Asamblea, Iglesias explicó esa perspectiva de proceso constituyente en términos de reconstrucción de la soberanía popular, blindaje constitucional de derechos y prestaciones sociales, consulta sobre la forma de Estado, revisión de la ley electoral o reconocimiento del derecho de autodeterminación. Esta perspectiva coincidía con los objetivos de «democracia política y social» formulados en el Manifiesto Programa del PCE de 1975.

56 J. C. Monedero, La Transición contada a nuestros padres. Nocturno de la democracia española, Madrid, Catarata, 2013, pp. 19-29, 226 y 243-254. 
La correspondencia entre el escenario de ocaso de la dictadura y la situación sociopolítica vivida en 2014 fue objeto de otras lecturas en el entorno político-intelectual de Podemos. Este fue el caso de la efectuada por Jaime Pastor y Miguel Urbán - ambos dirigentes de IzAn - , que desestimaron la capacidad de regeneración reformista del sistema actual, denunciaron el «triple consenso» sobre pasado, presente y futuro a su juicio impuesto en 1978, y propugnaron la recuperación de una noción polivalente (cultural, política y socioeconómica) de ruptura. Ello otorgaría a la Transición, según estos autores, un cierto sentido de paréntesis histórico, al tiempo que permitía destacar la crítica a la colaboración de Santiago Carrillo y el aparato dirigente del PCE en la estrategia reformista desde inicios de $1976^{57}$. Ahondando en esta misma interpretación, y fijando el foco en la movilización obrera, estudiantil y vecinal de mediados de los años setenta, Emmanuel Rodríguez ha insistido igualmente en el potencial democrático de lo que ha definido como ciclo movilizador desde abajo, particularmente protagonizado por los trabajadores industriales, frente a los ejercicios de neutralización desarrollados desde las elites políticas entre 1976 y 1978, y también frente al discurso de normalización y consenso social manejado por el relato idealizador de la Transición ${ }^{58}$.

Otras interpretaciones reactualizaron algún vocablo más del léxico antifranquista, al tiempo que han resaltado los puntos de referencia internacional donde situar la ruptura como proyecto de futuro. Así, según Raúl Zelik, la estrategia de la formación podría encuadrarse en relación con el viejo ideal de revolución democrática defendida por el PCE en 1972-73 y, simultáneamente, en conexión con las experiencias de Venezuela, Ecuador o Bolivia, definidas como «rebeliones populares rupturistas» ${ }^{59}$. Para Gerardo Pisarello, miembro de Procés Constituent e impulsor de la plataforma electoral Guanyem Barcelona/Barcelona en Comú, la dimensión histórica de ruptura cabría vincularla con las experiencias españolas de 1878 y 1931 y como «regreso de un espectro» frente al paradigma de Transición insuperable, en un marco de tensión entre dinámicas constituyentes y de-

57 M. Urbán y J. Pastor, «¿Reforma o ruptura constituyente?», Viento Sur, 7 de diciembre de 2014 (disponible en http://www.vientosur.info/spip.php?article9631).

58 E. Rodríguez, Por qué fracasó la democracia en España. La transición y el régimen del 78, Madrid, Traficantes de Sueños, 2014.

59 R. Zelik, «Podemos y la «revolución democrática» en el Estado», Naiz, 7 de enero de 2015 (disponible en http://www.vientosur.info/spip.php?page=imprimir_articulo\&id_ article=9717). 
constituyentes $^{60}$. Ejemplos de lo primero serían los procesos de reestructuración tras la II Guerra Mundial en Francia o Italia, o en Portugal después del 25 de Abril. Las dinámicas deconstituyentes se caracterizarían, en cambio, por una naturaleza des-democratizadora. Una muestra sería el progresivo vaciado de las posibilidades más progresistas de la Constitución de 1978, hasta la revisión restrictiva del artículo 135 establecida en 2011.

Durante el inicio y los meses centrales de 2015 se sistematizó de forma más articulada, y ya claramente como reflexión orgánica, la lectura que ha seguido insistiendo en el agotamiento del ciclo político, económico o cultural transicional, o que establece paralelismos y diferencias entre las coyunturas de 1976-77 y 2008-15. El cauce esencial para estas reflexiones ha sido La Circular, una publicación promovida desde el Instituto 25M Democracia, el think tank de Podemos. En algunos escritos se han resaltado nuevos paralelismos entre el valor simbólico protagonista del PCE y Podemos en ambos contextos históricos, por ejemplo en lo relativo a la instrumentalización del miedo desde sectores conservadores, en un caso en relación con los fantasmas de la Guerra Civil y la vinculación a la Unión Soviética y en el otro respecto al «fantasma de Venezuela» ${ }^{61}$. En otros textos, en cambio, se ha apuntado la existencia de un inventario de expresiones rupturistas susceptibles de prologarse en el tiempo, más allá del carácter restrictivo como pacto reformista entre élites asignado a la estricta dimensión del cambio político. «En los setenta se luchó por lograr múltiples derechos», ha apuntado Germán Labrador, «(al) derecho al cuerpo, a la ciudad y al espacio público, y el derecho a la memoria, a la belleza o a la cultura (burguesa)». Tales demandas tomaron forma desde «la ocupación de un prado para una pista deportiva al pintado de murales, (o mediante) la recuperación de fiestas populares prohibidas, la retirada de estatuas ecuestres, la exploración de nuevas formas de amar o el aprendizaje de lenguas perseguidas». La conclusión última sería que «cuando la política en los años setenta se puso a hablar de consenso, la cultura seguía hablando de ruptura ${ }^{62}$.

${ }^{60}$ G. Pisarello, Procesos constituyentes. Caminos para la ruptura constituyente, Madrid, Trotta, 2014, pp. 11-20.

61 J. A. Andrade, «La transición ayer, la transición hoy», La Circular, 2, 2015 (disponible en http://lacircular.info/la-transicion-ayer-la-transicion-hoy/).

62 G. Labrador, «La cultura en transición y la Cultura de la Transición (CT)», La Circular, 2, 2015 (disponible en http://lacircular.info/la-cultura-en-transicion-y-la-cultura-dela-transicion-ct/). 
Este balance último reiteraría, pues, las tres claves medulares presentes en el uso público de la historia desde el entorno intelectual y político de Podemos: la naturaleza dicotómica de las dinámicas de cambio en la esfera política (reforma) y en los anhelos de la esfera pública (ruptura) durante los años centrales de la década de los setenta; el acusado sesgo popular y espontáneo de tales anhelos, que permite conectarlos existencialmente con el 15M; y, asimismo, una clara nostalgia idealizadora de esa imagen evocadora de ruptura que eclosiona desde abajo, pero que se vio bloqueada por las que han sido insistentemente presentadas como operaciones políticas restrictivas operadas desde arriba.

\section{Conclusiones. Podemos y la anamnesis de la ruptura}

Podemos sacudió la arena política española en 2014. Fruto de una lectura sobre el potencial disruptivo del $15 \mathrm{M}$ y las experiencias latinoamericanas, fundamentó su estrategia en conformar un discurso populista que se imbricase y transcendiese las señas de identidad del etiquetaje político y cultural clásico de la izquierda. La apelación a la transversalidad y a ocupar la «centralidad del tablero», el papel secundario concedido a la reivindicación social frente al objetivo de configurarse como maquinaria electoral, la invisibilidad otorgada al obrerismo o al republicanismo, el empleo de términos como soberanía popular o patriotismo... Todas estas marcas discursivas establecían abiertas distancias con el vocabulario sentimental e identitario tradicional de izquierda española de las últimas décadas. A ello se añadió la apuesta por una destacada presencia mediática que proyectase y apuntalase lo que Ernesto Laclau denominó como «liderazgo espectacular simbólico», entendido como instancia de representación de insatisfechos y de producción de símbolos compartidos ${ }^{63}$.

Sin embargo, el Podemos de 2014 asimismo enraizó con múltiples narrativas anteriores, dando definitiva traducción política y proyección pública al enfoque contra-memorístico e historiográfico de la crítica frontal a la Transición. Su relato partió de la naturalización de significados inversos a los habituales: hablar de quiebras y no de consensos; destacar el divorcio entre ciudadanía y elites; trastocar a los políticos en casta y a la democracia en régimen; explicar la Constitución como regresión... En esta

${ }^{63}$ Laclau, op. cit., 202. 
lógica, la noción de ruptura en el Podemos de 2014 puede advertirse como significante que pretendía sintetizar las fracturas generadas por la crisis y la desafección ciudadana, pero igualmente como clave de bóveda para generar un sistema de rearticulación discursiva mucho más amplio. En estas coordenadas habría tenido cabida, incluso, un cierto regreso a un imaginario simbólico de raíz protocapitalista, donde el eje de distinción izquierda/ derecha quedaría sustituido por una retórica mucho más elemental de ubicación arriba/abajo ${ }^{64}$.

Es en este juego de oposiciones e inversiones semánticas donde debe emplazar la revalorización del término ruptura entendida como «llave del candado del 78». No obstante, el discurso de Podemos de aquellos meses también estableció una ambigua relación con la interpretación historiográfica. Por un lado, porque asumió un enfoque revisionista radical que puede ser tildado de anacrónico, que discutió tanto el papel providencialista de las elites como el soporte sociológico - activo o pasivo- favorable al proceso reformista. Y, por otra parte, porque otorgó sentido y entidad de presente a la historiografía crítica que tipificó la Transición no como modelo, sino como anomalía.

Tal perspectiva facilita enlazar el discurso contra-memorístico manejado por Podemos sobre la ruptura con buena parte de las demandas memorialistas antifranquistas que eclosionaron a finales de los años noventa. Es desde esta base desde donde se produjo asimismo el engarce, en términos de recuerdo vicario, entre Podemos y las experiencias de la izquierda radical o del PCE anterior a 1976. «Muchos de los dirigentes de Podemos son hijos nuestros», afirmó en febrero de 2015 el ex secretario general comunista Julio Anguita, «y les reconozco la capacidad (...) de situarse en el frente de la ruptura». «El problema (ha estado) en que el salto de la resistencia a la ruptura no llegó a ponerse de actualidad hasta ahora», consideró, a su vez, Jaime Pastor a finales de $2014^{65}$. Ambos nombres formaron parte de la generación militante de la Transición, aunque evidenciaron tra-

${ }^{64}$ R. Cid, «Podemos \# Trending Topic», en E. Mateo (Ed.), Hasta luego Pablo. Once ensayos críticos sobre Podemos, Madrid, La Catarata, 2015, p. 9.

${ }_{65}$ F. R. Cardador, «Pablo Iglesias es un sabio adaptador de Lenin a las circunstancias actuales», Diario de Cádiz, 11 de febrero de 2015 (disponible en http://www.diariodecadiz.es/article/andalucia/1957471/pablo/iglesias/es/sabio/adaptador/lenin/las/circunstancias/actuales.html); J. Pastor, «Culturas políticas, de ayer y de hoy, y Podemos», Viento Sur, 20 de diciembre de 2014 (disponible en http://www.vientosur.info/spip. php?article9667). 
yectorias diferenciadas. Sin embargo, los dos coincidieron en reconocerse en la estrategia de presente de Podemos en 2014 desde un mismo significante polivalente sobre pasado y futuro.

Este uso público de la historia debe correlacionarse con un ejercicio de modulación discursiva afín con la renovación generacional, y que, por tanto, ha trascendido una visión puramente nostálgica de la década de los setenta. En este sentido, cabe relacionar el discurso de memoria de Podemos con otras prácticas narrativas propias del populismo anti-austeridad o de la nueva izquierda y que se han fundamentado en nuevas cohortes sociodemográficas, como sería el caso de Syriza. Esta formación reivindicó en 2014 o 2015 diversos hitos o lugares de memoria, como a los estudiantes muertos en 1973 en Atenas durante las protestas contra la Dictadura de los Coroneles. Sin embargo, su política de memoria ha sido mucho más cauta respecto a los hechos traumáticos ligados a la Guerra Civil griega, en parte por las profundas tensiones ideológicas existentes dentro de la izquierda helena entre Syriza y el Partido Comunista tradicional (KKE). Paralelamente, si bien el Podemos de 2014 rehuyó el etiquetaje simbólico con los emblemas prototípicos de la tradición de izquierdas en aras de la transversalidad, su estrategia fue posible gracias al vacío generado por la crisis de esas mismas organizaciones, en particular IU. Parte importante de la «ventana de oportunidad» tuvo que ver con su aparente agotamiento, así como con la desafección de sectores notables del electorado con el PSOE.

El prolongado ciclo electoral vivido entre la primavera de 2015 y el verano de 2016 ha terminado de evidenciar tres aspectos más que permiten concluir la reflexión presentada en estas páginas. Por un lado, durante aquellos meses se produjo la consolidación de Podemos como oferta electoral, si bien como fórmula cada vez más escorada en su discurso público hacia un espacio sociológico y electoral de izquierdas. En segundo término, esta dinámica relativizó su sesgo transversal, incluyendo desde 2015 frecuentes apelaciones a la tradición socialdemócrata o, incluso, a la «izquierda transformadora», en coherencia con la estrategia, a la postre fallida, desplegada en las elecciones del 26 de junio de 2016 por convertirse en fuerza hegemónica de la izquierda española. Y, finalmente, esa misma estrategia se vio acompañada por prácticas de un revisionismo dúctil respecto a la cualificación crítica de la Transición y a la reivindicación alternativa de la ruptura democrática.

Tal reconsideración sirvió de eje para el conjunto de textos de coyuntura reunidos en un trabajo publicado en vísperas de las elecciones 
del 20 de diciembre de $2015^{66}$, y fue expresamente evidenciada por Pablo Iglesias en una intervención celebrada durante la precampaña electoral de aquellos comicios en la que renunciaba a una reforma integral de la Constitución de 1978 y «admitía los logros de la Transición». Casi en paralelo, en relación con la conmemoración del 6 de Diciembre, Iglesias realizó una apelación al «compromiso histórico». Aquella otra categoría era evidentemente vinculable con el capital simbólico del eurocomunismo mediterráneo. Sin embargo, fue evocada no sólo como referente histórico, sino ante todo como recurso de memoria propio de la nueva política a través de una noción ambigua y descontextualizada en forma de significante vacío ${ }^{67}$.

${ }^{66}$ P. Iglesias, Una nueva transición. Materiales del año del cambio, Madrid, Akal, 2015. Entre aquellos textos destacaba el titulado «Una nueva transición», publicado en $E l$ País el 19 de julio de 2015 y que, en buena medida, se fundamentaba en lo escrito meses antes para New Left Review.

67 «Iglesias renuncia a una reforma integral de la Constitución y admite los logros de la Transición», y P. Iglesias, «Un nuevo compromiso histórico», El País, 21 de noviembre y 9 de diciembre de 2015 . 